\title{
An Electrospray Ion Source for Magnetic Sector Mass Spectrometers
}

\author{
Barbara S. Larsen and Charles N. McEwen \\ E. I. du Pont de Nemours \& Company, Inc., Central Research and Development Department, \\ Wilmington, Delaware, USA
}

Electrospray mass spectra of carbonic anhydrase (MW - 29000) and ovalbumin (MW 45000) were obtained on a double focusing magnetic secter mass spectrometer by using a single stage of mechanical pumping in the interface between atmospheric pressure and high vacuum. Full scan spectra of lysozyme were recorded on 15 fmoles consumed. In addition, accurate mass measurement was demonstrated for peptides and proteins, and resolution in excess of $10,000(\mathrm{~m} / \Delta \mathrm{m}, 10 \%$ valley) was observed. These results clearly show that high performance magnetic sector mass spectrometers can be advantageously interfaced to an atmospheric pressure electrospray ion source. (J Am Soc Mass Spectrom 1991, 2, 205-211)

$\mathrm{E}$ lectrospray ionization combined with quadrupole mass spectrometers has been phenomenally successful in obtaining molecular weights of peptides and proteins, even some exceeding 50,000 $u[1,2]$. As a result of the success of electrospray ionization in producing multiply charged molecular ions of such highly polar materials, there has been considerable effort made to interface the technique to other types of instrumentation, including tandem triple quadrupole/Fourier transform mass spectrometry instruments $[3,4]$, magnetic sector instruments [5-9], and quadrupole ion traps [10].

We previously reported results from interfacing electrospray ionization to a double focusing magnetic sector mass spectrometer along with the potential advantages of this instrumentation, including better resolution and mass accuracy, and the potential for high energy collision-induced dissociation of the multiply charged ions $[6,7]$. Here we include the possibility of better sensitivity with a sector instrument than can be obtaincd with standard quadrupole instruments. In addition, a large number of laboratories have magnetic sector instruments and need the capabilities provided by electrospray ionization without the expense of purchasing a new mass spectrometer.

Initial experiments with electrospray ionization on a high performance magnetic sector mass spectrometer began with a single stage of mechanical pumping in the interface between atmospheric pressure and the high vacuum uf the source housing [6]. Baffles were included to prevent discharging to the pump. The

Address reprint requests to Barbara S. Larsen, E. I. du Pont de Nemours \& Company, Inc, Central Research and Development Deparment, P.O. Box 80228, Wilmington, DE 19880-0288. early design required the pressure in the region between the skimmer and the end of capillary to be above 10 torr to prevent discharging. A low pressure in the ion acceleration region could be achieved by restricting the size of the skimmer aperture, but because of concerns about sacrificing ion transmission the aperture was made as large as possible while maintaining an operational pressure in the source housing region (ca. $1 \times 10^{-3}$ torr). Spectra for small molecules were reported [6], but with this source design highly charged ions were not observed.

The pressure was reduced (ca. $1 \times 10^{-4}$ torr) in the high voltage ion acceleration region of the source $[6$, 7] by incorporating a second mechanical pumping stage between the end of the capillary and the skimmer. With this two-stage pumping interface, similar sensitivities for peptides were demonstrated by using electrospray ionization interfaced to a magnetic sector instrument as were reported for quadrupole instruments. However, multiply charged ion from proteins still were not observed. The maximum number of charges observed on a single molecule with this interface was eight for ubiquitin (MW 8451) [7].

A further reduction in pressure was thought to be necessary to reduce ion-molecule collisions in the region of kilovolt ion acceleration [6]. This was achieved by removing the baffles to allow better gas conductance and electrically isolating the mechanical pump from ground to prevent electrical discharges. Under these conditions with a single-stage of pumping, a pressure of $5 \times 10^{-5}$ torr was achieved and the electrospray mass spectra of myoglobin (MW 16950) was reported [11].

Recently, Gallagher et al. [8] reported the electrospray spectrum of bovine albumin (MW 66300) ob- 
tained on a double focusing magnetic sector instrument operated at $2 \mathrm{kV}$. For this work, they employed an interface with two-stages of pumping before the source high vacuum region. By using a turbomolecular pump in the second pumping stage, a vacuum of $3 \times 10^{-6}$ torr was achieved in the source housing region.

In this article we describe the essentials of a simplified electrospray ion source interfaced to a high voltage magnetic sector mass spectrometer that works routinely for peptides and small proteins. Resolution, mass accuracy, and sensitivity are demonstrated, and the spectra of carbonic anhydrase (MW 29000) and egg albumin (MW - 45000) are shown.

\section{Experimental}

The electrospray ion source was obtained from Analytica of Branford (Branford, CT) for operation on a VG ZAB-E double focusing high field mass spectrometer (VG Analytical Ltd., Manchester, UK). The source as received was modified by removing the baffles that acted to suppress discharges [6] but also severely restricted the pumping efficiency between the exit-end of the capillary and skimmer. The pressure in the furst pumping stage was still sufficiently high to observe discharges, therefore the rotary pump, Edwards ED660 (Wilmington, MA) with 2" pumping lines, was isolated from the motor drive using a plywood mounting and a Delrin (DuPont Company, Wilmington, DE) pulley on the motor. The metal housing of the source itself was electrically isolated from the mass spectrometer by a nylon flange insert.

Typical operating conditions for the ion source, which is shown schematically in Figure 1 , are as follows: Electrospray needle (26S gauge), $4.6 \mathrm{kV}$; cylindrical electrode, $1.2 \mathrm{kV}$; capillary entrance, 0.1 $\mathrm{kV}$; distance between needle and capillary entrance, $1.5 \mathrm{~mm}$; capillary exit, $5.18 \mathrm{kV}$; skimmer, $5.0 \mathrm{kV}$; first steering lens, $4.5 \mathrm{kV}$; second steering lens, $3.8 \mathrm{kV}$; bath gas, $\mathrm{N}_{2}$ maintained at ca. $50 \mathrm{cc} / \mathrm{min}$ at $60^{\circ}$; sample liquid flow rate, $1 \mu \mathrm{L} / \mathrm{min}$; using a Hamilton
Syringe Pump (Harvard Apparatus, Southnatich, MA) model 2000. The capillary was ca. $0.56 \mathrm{~mm}$ ID $\times 130$ $\mathrm{mm}$, and the skimmer orifice was ca. $0.36 \mathrm{~mm}$. The distance between the capillary-exit and the skimmer was ca. $3.0 \mathrm{~mm}$. The pressure between the capillaryexit and the skimmer was 0.6 torr measured at the pumping line. The source housing is pumped by the standard 6" Edwards diffstak diffusion pump supplied on the VG ZAB-E and is backed by an Edwards E2M18 rotary pump. The source housing pressure was $1.5 \times 10^{-5}$ torr.

Mass spectra were acquired on a VG 11-250 data system and further processed on VG OPUS workstation. The spectra shown are an accumulation of several scans unless otherwise noted. Full scan mass spectra were acquired by scanning $2500-500 \mathrm{u}$ at 30 $\mathrm{sec} / \mathrm{dec}$ at a resolution of 1000 except where otherwise indicated.

The peptides and proteins were purchased from Sigma Chemical Company (St. Louis, MO) and run without further purification. Polyethylene glycol (PEG) 1000 used for calibration purposes was obtained from Aldrich Chemical Company Inc. (Milwaukee, WI). A standard solvent of 1:1 (v:v) methanol:water $0 \%-5 \%$ acetic acid was used. Mass spectra were acquired using solutions of sample concentration $<10 \mathrm{pmol} / \mu \mathrm{L}$.

\section{Results and Discussion}

The electrospray interface for a high performance magnetic sector mass spectrometer was modified to improve the pumping efficiency by removing the baffles from the source, Removal of the baffles increases the pumping capability but requires that the mechanical pump and the metal source housing be electrically isolated to prevent discharges in the pumping line. (Building the source housing of nonconductive materials is highly recommended for safety reasons.) The lower pressure $\left(5 \times 10^{-5}\right.$ torr, $0.56 \mathrm{~mm}$ skimmer aperture) achieved with this source design (Figure 1) relative to the previously reported [7] two-
Figure 1. Schematic of a single pumping stage electrospray ion source that achieves a source housing pressure of $1.5 \times 10^{-5}$ torr by using unrestricted mechanical pumping and a $360 \mu$ skimmer aperture.

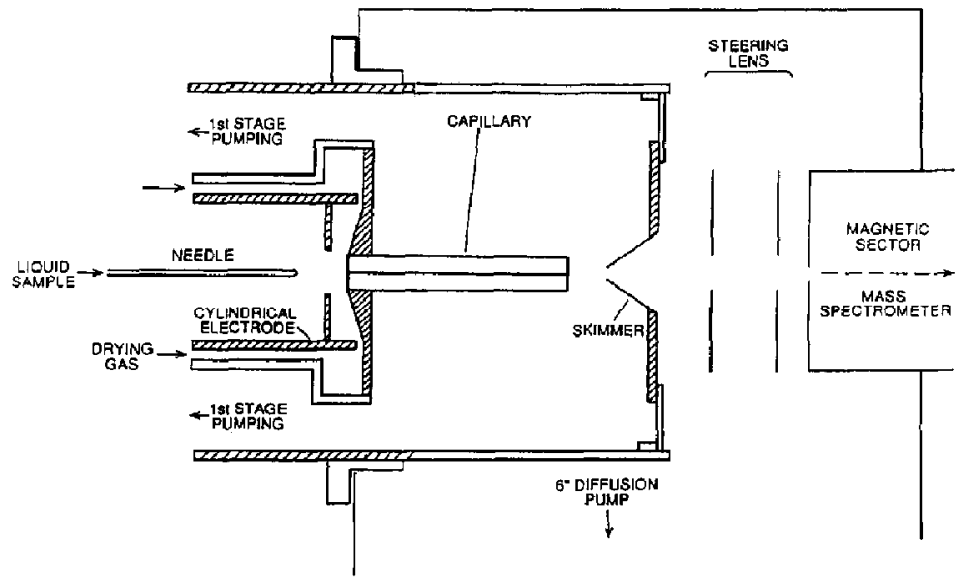




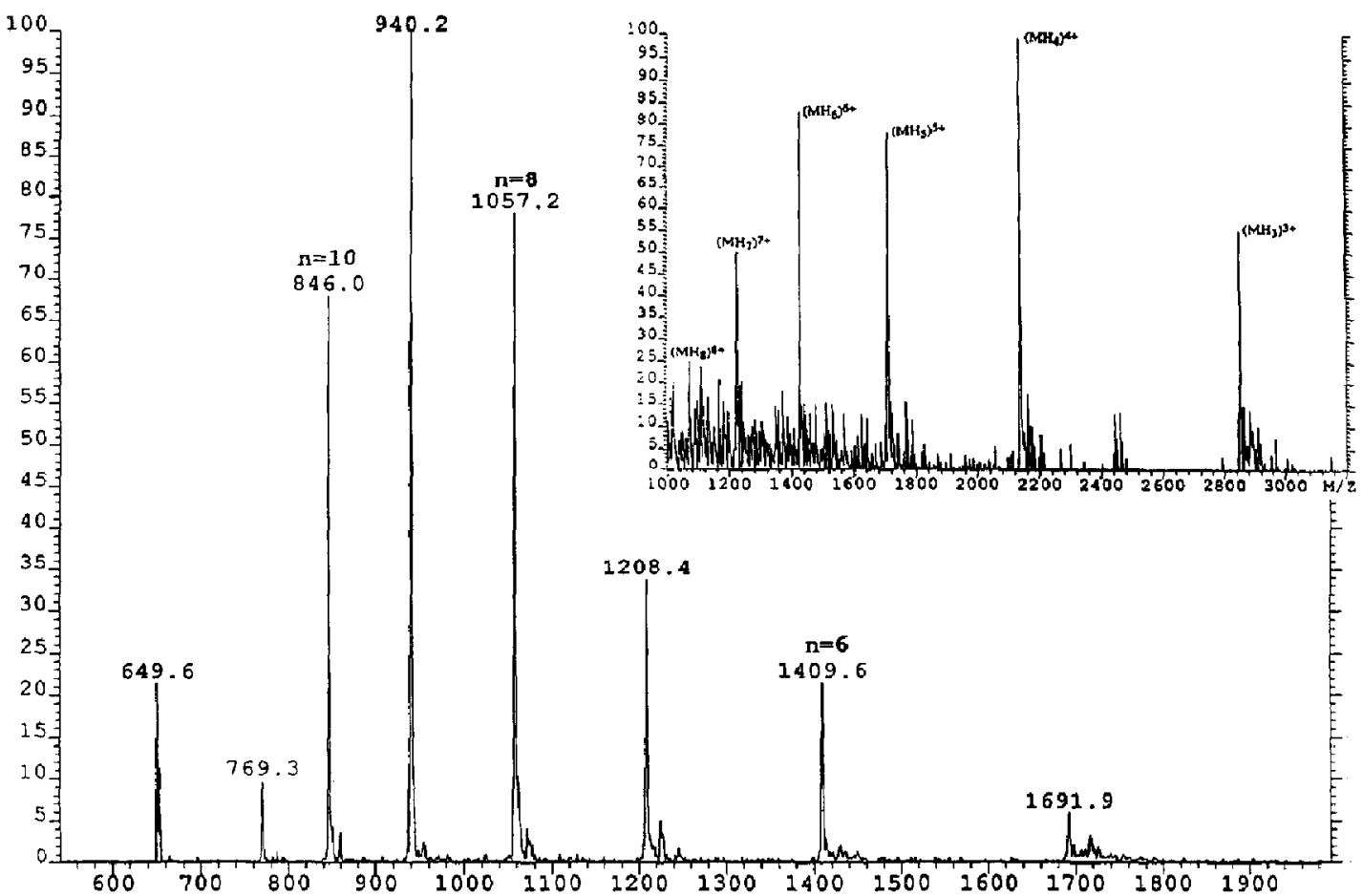

Figure 2. Electrospray mass spectrum of ubiquitin consuming approximately 5 pmoles at a concentration of 2 pmole $/ \mu \mathrm{L}$. Inset shows a spectrum of ubiquitin abtained with an earlier source design [6] where the pressure in the source vacuum regions was higher.

stage design with baffles provides more intense spectra of ubiquitin and ions of higher charge state. In addition, the spectrum of myoglobin (MW 16950) was also obtained with this source [11].

The improved results observed with the electro- spray interface with the baffles removed was thought to be the result of reduced pressure, especially in the critical source housing region where a factor of two improvement was observed relative to the previous two-stage pumping design with baffles [7]. The reduc-

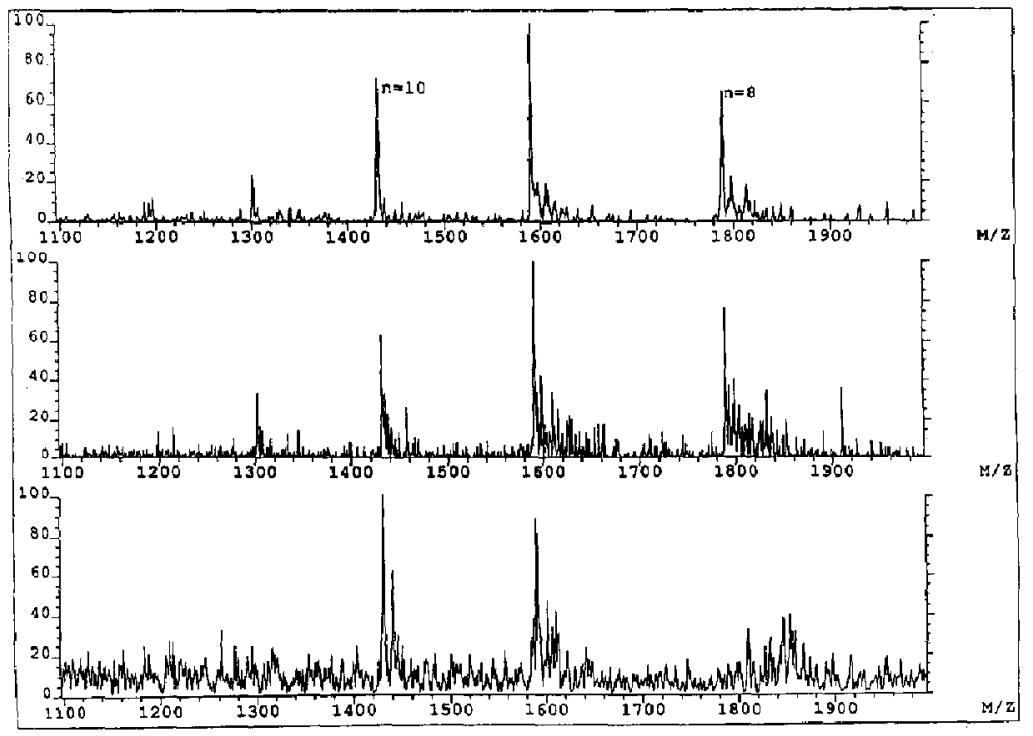

Figure 3. The electrospray mass spectra of lysozyme (MW 14305) obtained by consuming (a) 1 pmole at a concentration of 1 pmole $/ \mu \mathrm{L}$, (b) 60 fmole at 60 fmole/ $\mu \mathrm{L}$, and (c) 15 fmole at 60 fmole $/ \mu \mathrm{L}$, single $15 \mathrm{~s}$ scan. 
Figure 4. Electrospray mass spectrum of

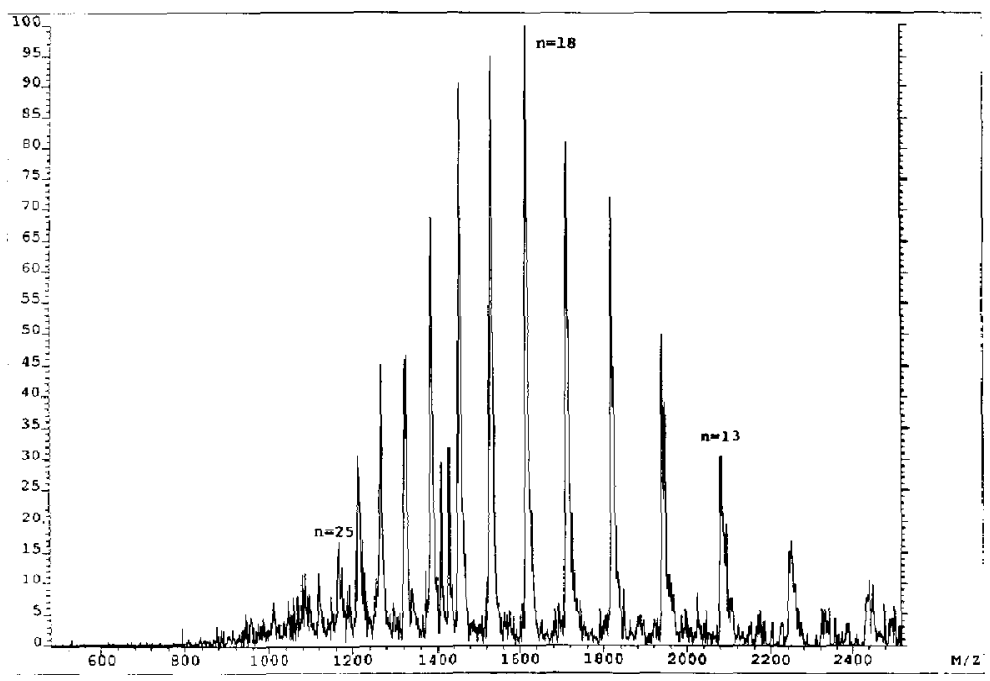
carbonic anhydrase (MW 29020).

tion in pressure results in less charge stripping in the low voltage region between the capillary-exit and the skimmer, and reduced collisional decomposition and scattering losses in the kilovolt ion acceleration region. It is obvious that the noise level of the more recently acquired spectrum of ubiquitin (Figure 2) is considerably reduced and the average charge state of the multiply charged molecular ions is increased relative to that obtained with the previous source design (Figure 2, inset) [7]. Nevertheless, proteins with higher molecular weights such as carbonic anhydrase (MW 29020) could not be observed with this single-stage interface.

A second stage of mechanical pumping was added to the source without baffles to provide a further reduction in pressure in the source housing region $\left(3 \times 10^{-5}\right.$ torr). This reduction in pressure provided better sensitivity for small proteins. Multiply charged ions for lysozyme were observed at a concentration of $60 \mathrm{fmole} / \mu \mathrm{L}(60 \mathrm{fm}$ consumed). With the two stages of mechanical pumping, a mass spectrum for carbonic anhydrase was obtained but the poor quality of the spectrum suggested that the pressure in the ion acceleration region was still a problem.

Interestingly, the best results were obtained using the interface (Figure 1) with only a singlc stage of mechanical pumping but with a more restrictive skimmer orifice $(0.36 \mathrm{~mm})$ than previously used. The pressure was further reduced with this arrangement (1.5 $\times 10^{-5}$ torr), and reasonable quality spectra were obtained for Iysozyme at 15 fmole consumed (Figure 3 ). This result is especially encouraging in view of the
Figure 5. Electrospray mass spectrum of ovalbumin (MW 45000) showing heterogeneity due to glycosylation at Asn-292 [12].

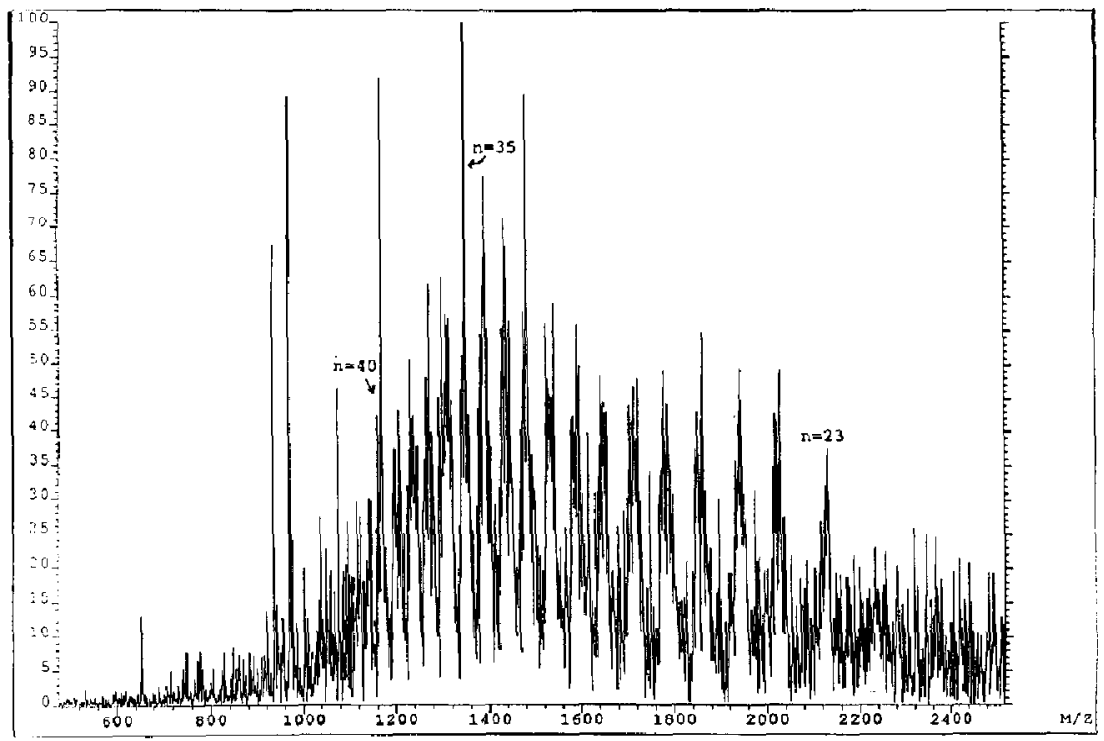


possibility that similar spectra could be acquired on a magnetic sector instrument with a reduction in material consumed by up to two orders of magnitude by using array detection! Larger proteins were also observed with this source arrangement. The mass spectrum of bovine carbonic anhydrase (MW ca. 29000) is shown in Figure 4 and of ovalbumin (MW ca. 45000) in Figure 5. Ovalbumin is phosphorylated and glycosylated [12] and the spectrum clearly shows it to be a heterogenous mixture.

Resolution is demonstrated (Figure 6 top) on the doubly charged ion envelope of bradykinin acquired under full scan conditions at 5000 static resolution. At the same resolution, the quintuply charged molecular ion of insulin is resolved (apparent dynamic resolution 4000 , Figure 7 top). The theoretical isotopic distri- bution at 5000 resolution is shown for bradykinin (Figure 6 bottom) and 4000 resolution for insulin (Figure 7 bottom). A static resolution of $10000(\mathrm{~m} / \Delta \mathrm{m}$, $10 \%$ valley) was achieved for bradykinin with similar reduction in ion transmission through the analyzer, as is observed using the standard electron impact source. At this stage of electrospray development the ca. twentyfold loss in ion transmission in obtaining 10,000 resolution is too severe to be of practical use, especially for proteins.

Full scan mass accuracy is demonstrated with a mixture of bradykinin and angiotensen II. Mass accuracy using PEG 1000 as an internal reference is typically better than $20 \mathrm{ppm}$ at ca. 1000 resolution (Table 1). The mass accuracy for the unresolved molecular ions of insulin are typically less than $30 \mathrm{ppm}$. For

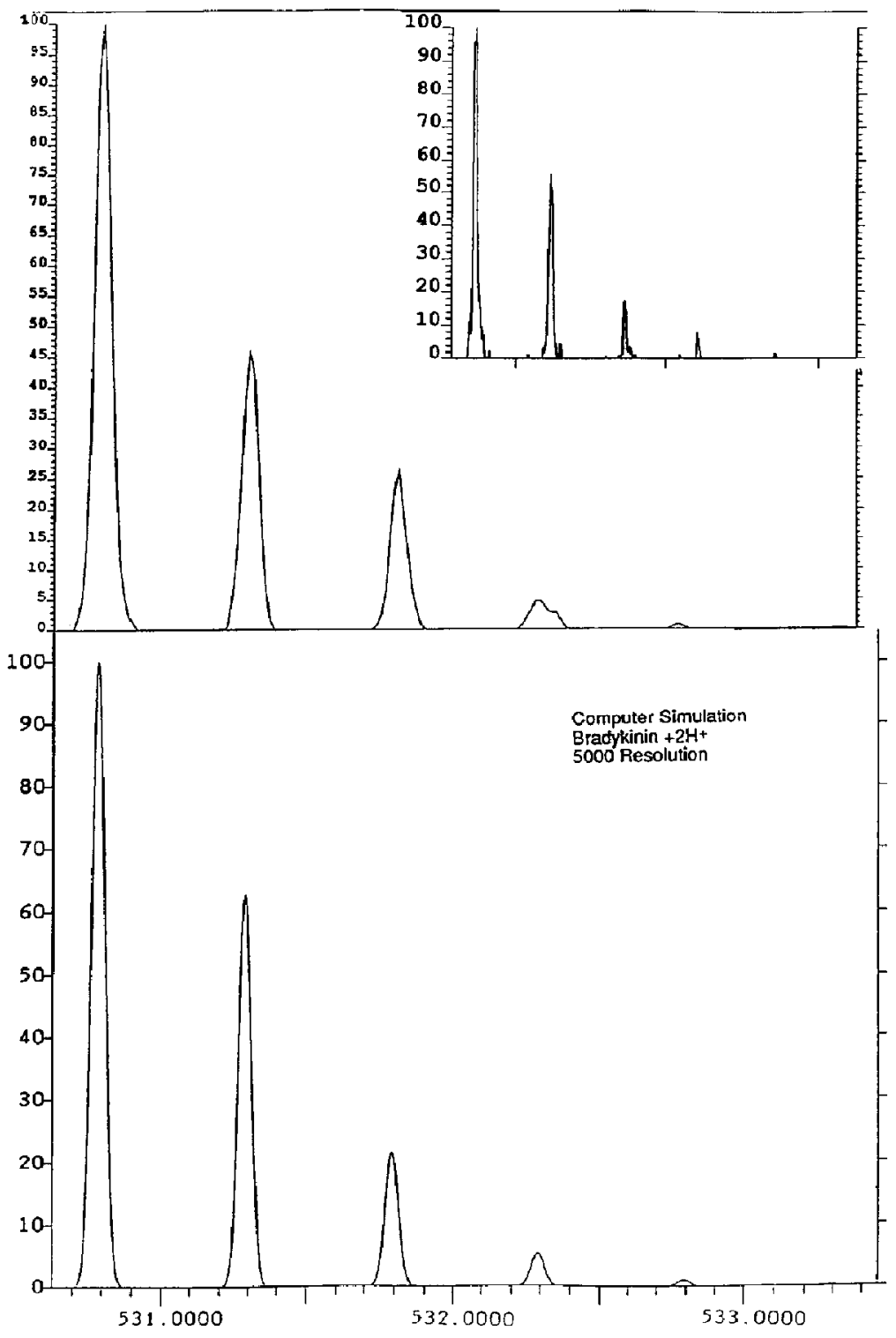

Figure 6. (Top) Expansion of the doubly charged molecular ion region from the $30 \mathrm{sec} / \mathrm{dec}$ full scan electrospray mass spectrum of bradykinin (MW 1059) obtained at $5000(\mathrm{~m} / \Delta \mathrm{m}, 10 \%$ valley) static resolution. Inset shows the doubly charged ion envelope at 10,000 static resolution. (Bottom) Theoretical isotopic distribution at 5000 resolution for the doubly charged molecular ion for bradykinin. 
Figure 7. (Top) Single $3000 \mathrm{sec} / \mathrm{dec}$ scan over the quintuply charged molecular ion region of insulin. The instrument was tuned to 5000 static resolution on the doubly charged ion of bradykinin. (Bottom) Theoretical isotopic distribution at 4000 resolution $(\mathrm{m} / \Delta \mathrm{m}, 10 \% \mathrm{val}$ ley) for the quintuply charged molecular ion of insulin.

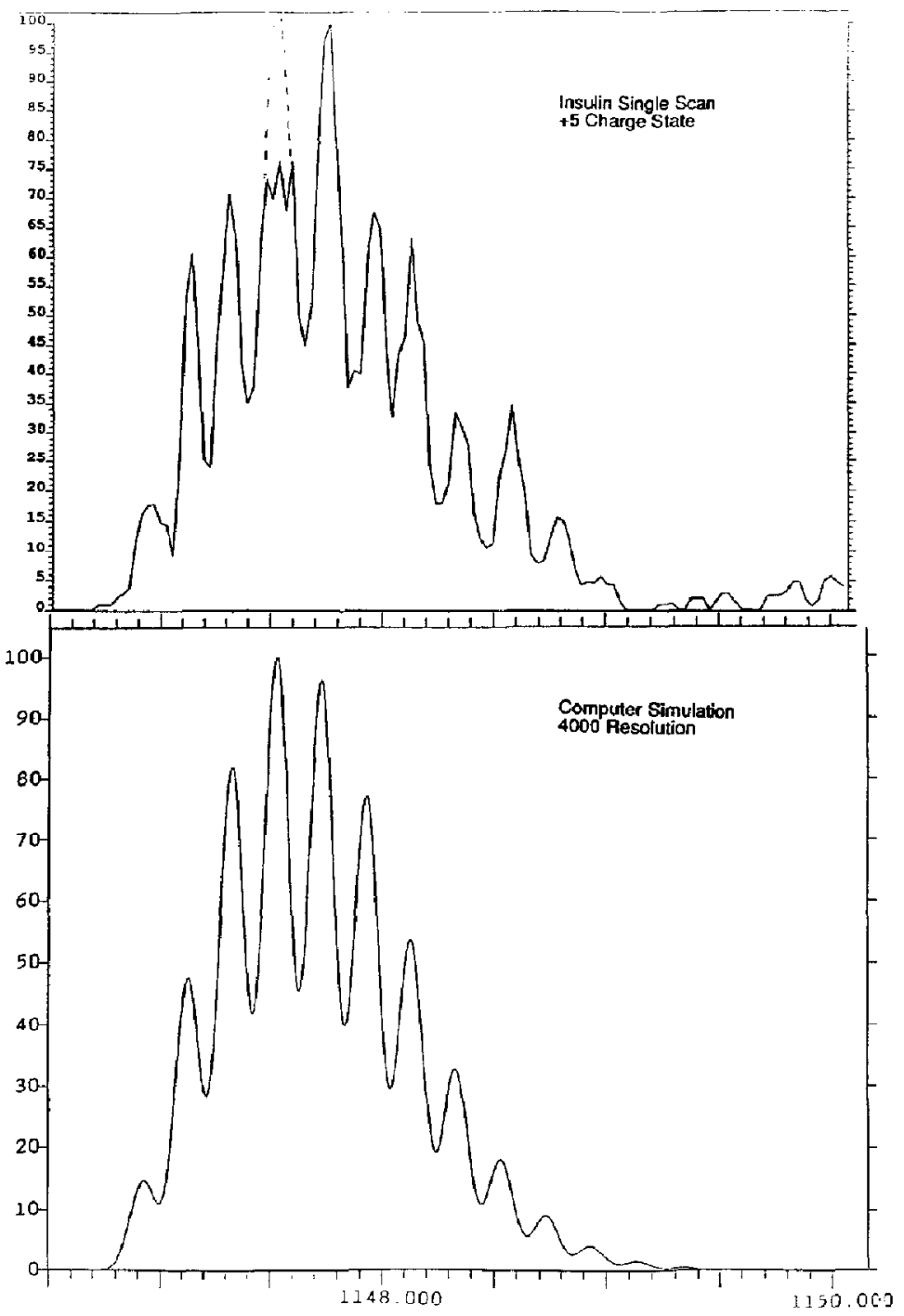

higher mass peptides, the error for any single meastirement increases, but because there are ustually a large number of multiply charged molecular ions, the averaged mass seldom exceeds $25 \mathrm{ppm}$ for pure peptides with molecular weights below 10000 . For exam- ple, the synthetic peptide, $\alpha 4-P C R G$ resulted in an average measured mass of 8612.42 , which compares well to the calculated mass of 8612.50 (Table 1). The major problems in achieving high mass accuracy are in obtaining sufficient ion signal for both the sample

Table 1. Full scan accurate mass measurement data obtained by using polyethylene glycol 1000 as an internal reference

\begin{tabular}{lclcc}
\hline $\begin{array}{c}\text { Compound } \\
\text { name }\end{array}$ & $\begin{array}{c}\text { Measured } \\
\text { mass-to-charge ratio }\end{array}$ & $\begin{array}{c}\text { Observed } \\
\text { MW }\end{array}$ & $\begin{array}{c}\text { Accurate } \\
\text { MW }\end{array}$ & Error (ppm) \\
\hline \hline Angiotensin II & 523.781 & 1045.546 & 1045.535 & 10 \\
Bradykinin & 530.780 & 1059.545 & 1059.561 & 15 \\
Insulin & 1147.70 & 5733.46 & 5733.60 & 24 \\
$\alpha 4-P C R G$ & $*$ & $8612.42 \pm 0.19$ & 8612.50 & 9 \\
\hline
\end{tabular}

*Calculated mass is an average of six mass-to-charge ratio measurements for the different multiply charged molecular ions observed in a single mass spectrum.

Abbreviations: MW, magnetic weight; ppm, parts per million. 
and reference to determine accurate centroids and underlying peaks that can shift the apparent mass. The use of internal reference materials that produce few background peaks is desirable. We will provide more details on the mechanics of obtaining accurate mass measurements for proteins in a subsequent article.

The results reported here strongly support the contention that the multiply charged ions produced during electrospray ionization of proteins are highly susceptible to collisional decomposition when accelerated through kilovolt potentials. By reducing the pressure in the region of high voltage ion acceleration, high resolution, good mass accuracy, and high sensitivity can be achieved with an electrospray ion source interfaced to a high performance magnetic sector mass spectrometer. The necessary pressures can be achieved using only a single-stage of mechanical pumping. Thus, with a relatively simple interface, the advantages of a high performance magnetic sector mass spectrometer can be realized for electrospray ionization.

\section{Acknowledgments}

We wish to thank Dr. Chin Kai Meng for his efforts in the early, difficult days, and we gratefully acknowledge Mrs. Phyllis Reid for her patience in assembling this manuscript.

\section{References}

1. Fenn, J. B.; Mann, M.; Meng, C.-K.; Wong, S.-F; Whitehouse, C. M. Science 1989, 246, 64.

2, Loo, J. A.; Udseth, H. R.; Smith, R. D. Anal. Biochem. 1989, 179, 404 .

3. Henry, K.D.; Williams, E. R.; Wang, B. H.; McLafferty, F. W.; Shabanowitz, J.; Hunt, D. F. Proc. Natl. Acad. Sci. USA 1989, 86, 9075.

4. Henry, K. D.; McLafferty, F. W. Org. Mass Spectrom. 1990, 25,490 .

5. Allen, M. H.; Lewis, I. A. S. Rapid Commun. Mass Spectrom. 1989, 3, 255-258.

6. Meng, C.-K.; McEwen, C. N.; Larsen, B. S.; Whitehouse, C. M.; Fenn, J. B. In Biological Mass Spectrometry; Burlingame, A. L.; McCloskey, J. A., Eds.; Elsevier: New York, 1990; p. 147.

7. Meng C.-K.; McEwen, C. N.; Larsen, B. S. Rapid Conmun. Mass Spectrom. 1990, 4, 147.

8. Gallagher, R. T.; Chapman, J. R.; M. Rapid Commun. Mass Spectrom. 1990, 4, 369 .

9. Lee, E. D.; Shumate, C. B.; Radolovich, G. Proceedings of the 38th ASMS Conference on Mass Spectrometry and Allied Topics; Tucson, AZ, 1990; p. 437.

10. Van Berkel, G. J.; Glish, G. L.; McLuckey, S. A. Anal. Chem. 1990, 62, 1284.

11. Larsen, B. S.; Meng, C.-K.; McEwen, C. N. Proceedings of the 38th ASMS Conference on Mass Spectrometry and Allied Topics; Tuscon, AZ, 1990, Pp. 128 and 435.

12. McReynolds, L.; OMalley, B. W.; Nisbet, A. D.; Futhergill, J. E.; Givol, D.; Fields, S.; Robertson, M.; Brownlee, G. G. Nature 1978, 273, 723. 